\title{
New Book on the Crystallographic Properties of All Elements Now Available
}

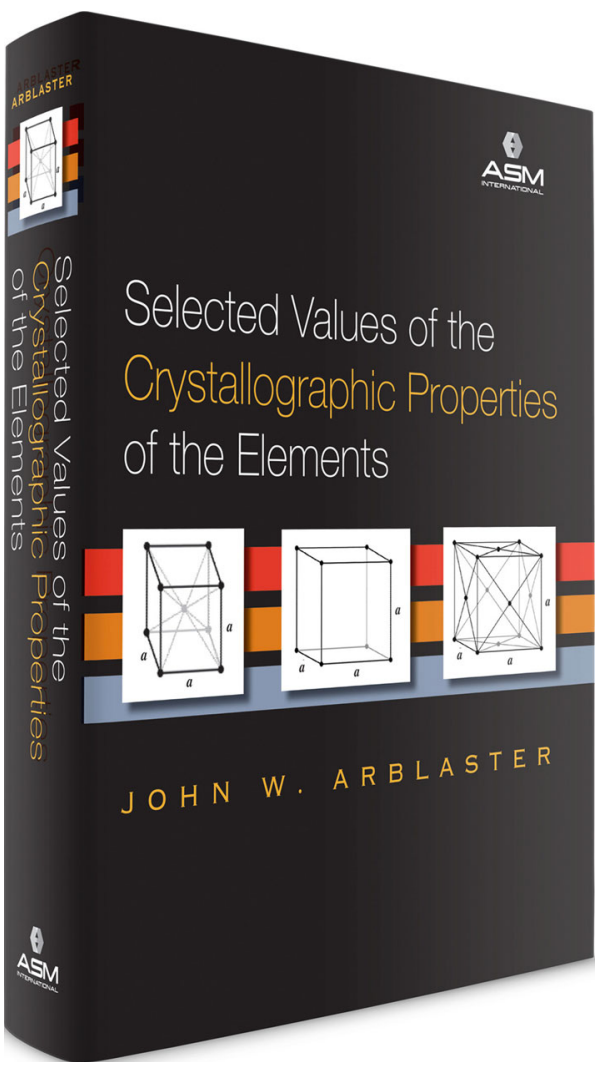

Selected Values of the Crystallographic Properties of the Elements by John W. Arblaster is now available. This reference book presents a unique and comprehensive review of the crystallographic properties of all the elements and will be a valuable resource for metallurgists and crystallographers. The crystallographic properties are evaluated at ambient pressure in order to provide a base line for high pressure studies. Lattice parameters are presented as a function of temperature and related properties such as thermal expansion coefficients, molar volumes, and densities are provided. Special attention is given to ensure that the selected values correspond to the latest values of atomic weights and the fundamental constants.

Author John Arblaster spent his career as a metallurgical chemist analyzing a wide variety of ferrous and nonferrous metals and alloys in a number of commercial laboratories. He first became interested in crystallography in order to solve the dispute over whether osmium or iridium was the densest metal in the room-temperature region. He showed, by proper application of up-to-date input data, that it was in fact osmium. He then produced comprehensive reviews on the crystallographic properties of the six platinum group of metals and has now extended this work to all of the elements.

The list price of Selected Values of the Crystallographic Properties of the Elements is \$249, but ASM Members can purchase the book at a discounted rate of $\$ 189$. The book can be purchased by visiting www.asminternational.org/ 05244G, or by calling the ASM International Service Center at 800.336.5152. 